\title{
INTESTINAL HELMINTH PARASITES OF THE GREY WOLF (CANIS LUPUS L.) IN SERBIA
}

\author{
Duško ĆIROVIĆ $^{1 *}$, Ivan PAVloviĆ ${ }^{2}$ and Aleksandra PENEZIĆ ${ }^{1}$ \\ ${ }^{1}$ Faculty of Biology, University of Belgrade, Studentski trg 16, 11000 Belgrade, Serbia; \\ ${ }^{2}$ Scientific Institute of Veterinary Medicine of Serbia, Belgrade, Serbia
}

(Received 29 September 2014; accepted 17 February 2015)

\begin{abstract}
The grey wolf (Canis lupus L.) is the most widespread large carnivore in Europe with large populations in the Eastern part of Europe and the Balkan Peninsula. In this study, a total of 102 wolves were examined for intestinal helminth parasites. The carcasses were collected within the Serbian part of the wolf's range during the period 2009-2014. Nine helminth species were found: one nematode, Toxocara canis (3.9\%), one trematode, Alaria alata $(1.0 \%)$, and seven cestodes, Taenia pisiformis $(1.0 \%)$, T. hydatigena $(9.8 \%)$, T. polyacantha $(2.9 \%)$, T. taeniaeformis (2.0\%), T. (syn. Multiceps) multiceps (3.9\%), T. serialis $(1.0 \%)$ and Mesocestoides litteratus (1.0\%). Taenia (syn. Hydatigera) taeniaeformis has been registered for the first time in a wolf from Europe. An overall moderate prevalence $(16.7 \%)$ of infected wolves was recorded. There was no statistically significant difference in prevalence between sexes. Of the years studied, the highest prevalence was found in 2014 (57.1\%). The maximum number of helminth species per host specimen was four.
\end{abstract} Serbia

Key words: Grey wolf, Canis lupus L., intestinal parasites, helminths,

Formerly the grey wolf (Canis lupus L.) had the largest distribution of all mammal species in the world. It was abundant across its range and occupied Eurasia (including Japan) and the entire North American continent (Boitani, 2000). Due to the widespread destruction of its habitats, eradication, and the decline of its natural prey, the wolf has disappeared from Central and Western Europe (Delibes, 1990; Randi et al., 2000; Randi, 2011) as well as from Japan. Large populations in Europe survived only in the Balkans and the Eastern part of the continent (Boitani, 2000; Lucchini et al., 2004), while two isolated populations persisted in Italy (Boitani, 1992) and on the Iberian Peninsula (Delibes, 1990). The Balkan wolf population represented the border between the large Eastern European population and the small Western European population.

*Corresponding author; E-mail: dcirovic@bio.bg.ac.rs; Phone: 00381 (11) 263-7024; Fax: 00381 (11) 263-8500 
The pan-European recovery of the wolf in the last few decades was possible mainly due to the legal protection of the species and its capability for longdistance dispersal (Boitani, 1992; Salvatori and Linnell, 2005; Ansorge et al., 2006). The intestinal helminth fauna of the wolf has been thoroughly studied in many different parts of its distribution range (Craig and Craig, 2005). In Europe, only recently have a few studies been carried out (Shimalov and Shimalov, 2000; Segovia et al., 2001; Segovia et al., 2003; Moks et al., 2006; Popiołek et al., 2007; Bagrade et al., 2009). Although some of the largest wolf populations in Europe can be found on the Balkan Peninsula, data regarding intestinal helminths from this part of its range are almost completely missing. The only existing information is based on a small sample size (6 wolves) from Greece (Papadopoulos et al., 1997).

The distribution of the wolf in Serbia comprises wooded, hilly and mountainous regions in the eastern, western and southern parts of the country. Also, a small isolated population exists in the region of South Banat (Fig. 1), in the south-eastern part of the Pannonian Plain (Milenković, 1997; Milenković et al., 2007). According to recent estimates, the size of the wolf population in Serbia is 700-800 specimens, and this population tends to be stable or slowly increasing (Milenković et al., 2007). According to the law, the wolf is an unprotected game species (closed season) with the exception of southern Banat, where it is strictly protected.

The aims of this study were to present the first data on intestinal helminth parasites of the wolf from Serbia based on a relatively large sample size, to present the prevalence of intestinal helminths, to compare it with the prevalence obtained in other European studies and with the prevalence of intestinal parasites in two other canid species from Serbia, the golden jackal (Canis aureus L.) and the red fox (Vulpes vulpes L.).

\section{Materials and methods}

\section{Collection and examination of wolves}

In co-operation with the local hunting associations, the carcasses of legally hunted wolves were collected throughout Serbia from January 2009 to March 2014. A total of 102 animals (57 males and 45 females) from 28 localities were collected (Fig. 1). Carcasses were obtained throughout the year (winter: $\mathrm{n}=72$, spring: $\mathrm{n}=14$, summer: $\mathrm{n}=2$, autumn: $\mathrm{n}=14$ ). The culling date, location and sex of each wolf were registered. After taking basic morphometric measurements of each individual, the stomach and intestinal tract were removed and immediately frozen at $-20{ }^{\circ} \mathrm{C}$. For safety reasons, the material was kept at $-80{ }^{\circ} \mathrm{C}$ for three days prior to thawing at room temperature and parasitological investigation in the laboratory of The Scientific Institute of Veterinary Medicine of Serbia. 


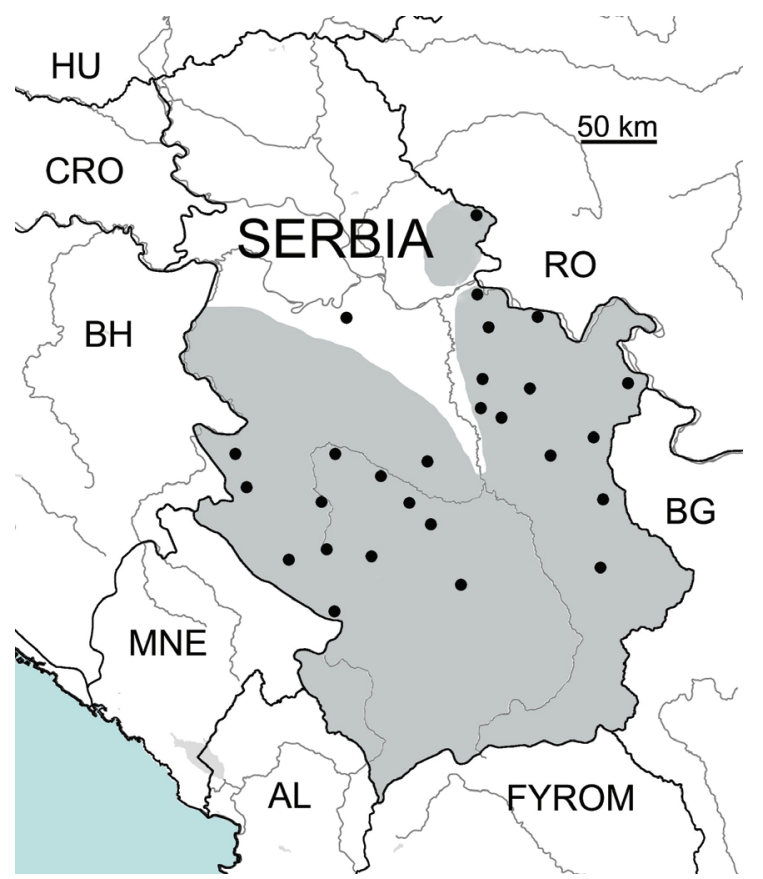

Fig. 1. Localities where samples were collected. The shaded area represents the distribution of the wolf in Serbia

The intestines were opened with a longitudinal incision. The entire content was removed and washed out with a water jet over a sieve with $200 \mu \mathrm{m}$ mesh openings. All visible parasites were transferred to Petri dishes. A wooden spatula or a microscope glass slide was used to scrape the intestinal walls in order to remove small parasites which were embedded in the mucosa. Firstly, all helminths were washed in warm water and then fixed: nematodes in $70 \%$ ethanol, cestodes and trematodes in a mixture composed of 5\% formalin, $85 \%$ ethanol and $10 \%$ glacial acetic acid. Nematodes were studied on depression slides using lactophenol-wet mounts. Cestodes and trematodes were stained with acetic carmine and mounted with Canada balsam after dehydration. Scolices of taeniids were severed and mounted in lactophenol and by pressing the cover glass the rostellar hooks were enabled to lie flat. Identification was based on the number, size, shape and arrangement of rostellar hooks. Determination of $T$. taeniaeformis was based on morphological characters. The lengths of the specimens and the width of both scolices were measured. The hooks on scolices were counted and measured. Immature, mature and gravid proglottids were recorded (Fig. 2). All helminths were identified using the relevant keys (Kozlov, 1977; Soulsby, 1982), counted and deposited in the collections of the Scientific Institute of Veterinary Medicine of Serbia and of the Faculty of Biology of the University of Belgrade. 


\section{Data analysis}

Prevalence $(\mathrm{P})$ as well as minimal and maximal intensities of occurrence were calculated according to Bush et al. (1997) and Rózsa et al. (2000). The chisquare test was used to compare the prevalence of intestinal helminths between sexes (Sokal and Rohlf, 1995). Data were analysed using Statistica 5.1 (Statsoft, Tulsa, OK, USA) with the level of significance being $\mathrm{P}<0.05$.

\section{Results}

In this study, 17 out of the 102 wolves examined were infected with intestinal helminths $(16.7 \%)$. In total, 84 individuals of 9 intestinal helminth species were found: one nematode, Toxocara canis, one trematode, Alaria alata, and seven cestodes, Taenia pisiformis, T. hydatigena, T. polyacantha, T. (syn. Hydatigera) taeniaeformis, T. (syn. Multiceps) multiceps, T. serialis and Mesocestoides litteratus. Our results indicate an overall low prevalence of all helminth species (Table 1). The most common parasite in the wolf population of Serbia was $T$. hydatigena $(9.8 \%)$ followed by $T$. multiceps $(3.9 \%), T$. canis $(3.9 \%), T$. polyacantha $(2.9 \%)$ and T. taeniaeformis $(2.0 \%)$. Taenia pisiformis, T. serialis, $M$. litteratus and A. alata were found only in one case each (1.0\%). The presence of $T$. taeniaeformis is recorded for the first time in wolves from the Palearctic ecozone. The length of these two specimens was 40.5 and $43.1 \mathrm{~cm}$, respectively. The scolex widths of both specimens were $1.6 \mathrm{~mm}$. Scolices were made up of four large suckers arranged side by side. The suckers were prominent, facing outwards and forwards. The rostella were short and armed with hooks strung alternately in two wreaths with 32 and 34 hooks, respectively. The large hooks were between 0.35 and $0.40 \mathrm{~mm}$ and the small ones between 0.22 and $0.27 \mathrm{~mm}$ in length. Characteristic appearance with the absence of a neck and with bellshaped posterior proglottids was recorded. The first proglottids were very short, the ones after them equally long and wide and the last ones significantly longer than wide (in the present case they were $8-10 \mathrm{~mm}$ long and 4-6 mm wide). In mature proglottids the uterine tree branch had a large number of lateral branches and affiliates (Fig. 2).

Most of the wolves $(n=12)$ were infected only with cestodes $(71 \%)$, while one animal $(5.9 \%)$ was infected only with nematodes. Four wolves $(23.5 \%)$ had mixed infection with cestodes and trematodes. Not a single animal was infected with trematodes only.

The majority $(64.7 \%)$ of infected wolves $(n=11)$ harboured only one parasite species, $4.7 \%(\mathrm{n}=5)$ had two parasite species and only $0.9 \%(\mathrm{n}=1)$ contained four helminth species. As regards seasons, the majority of infected wolves originated from the winter period $(n=14)$, while during the rest of the year only one wolf per season was infected (Table 2). This can be explained by 
the unequal number of samples examined in different seasons. The highest prevalence $(50 \%)$ was recorded during the summer (small sample size), followed by winter (17.7\%), autumn (14.3\%) and spring (7.1\%).

\section{Table 1}

Prevalence of intestinal helminth species of the wolf (Canis lupus L.) from Serbia

\begin{tabular}{lccc}
\hline Helminth species & $\begin{array}{c}\text { Number } \\
\text { of positive } \\
\text { findings }\end{array}$ & $\begin{array}{c}\text { Prevalence } \\
(\%)\end{array}$ & $\begin{array}{c}\text { Number } \\
\text { of helminths } \\
\text { (min.-max.) }\end{array}$ \\
\hline Cestoda & & & \\
$\quad$ Taenia pisiformis & 1 & 1 & 1 \\
Taenia hydatigena & 10 & 9.8 & $1-2$ \\
Taenia polyacantha & 3 & 2.9 & 1 \\
Taenia (syn. Hydatigera) taeniaeformis & 2 & 2 & 1 \\
Taenia (syn. Multiceps) multiceps & 4 & 3.9 & $1-2$ \\
Taenia serialis & 1 & 1 & 7 \\
Mesocestoides litteratus & 1 & 1 & 4 \\
\hline Trematoda & & & \\
$\quad$ Alaria alata & 1 & 1 & $4-19$ \\
\hline Nematoda & & & \\
$\quad$ Toxocara canis & 4 & 3.9 & \\
\hline
\end{tabular}

The highest prevalence (57.1\%) was recorded in 2014 when 4/7 wolves were infected, followed by 2013 (36.8\%; 7/19 infected wolves), 2012 (10.3\%; $3 / 29$ infected wolves), 2009 (15.4\%; $2 / 13$ infected wolves) and $2010(4.5 \% ; 1 / 22$ infected wolf). In 2011 there were no infected wolves (0/12; Table 2). The prevalence of infection was $19.3 \%$ in male wolves (11 out of 57 examined males) and $13.3 \%$ in females ( 6 out of 45 examined females). None of the above differences was statistically significant $\left(\chi^{2}=0.64, \mathrm{P}=0.422\right)$.

\section{Discussion}

All intestinal parasites found in this study are already known in Europe as parasites of the wolf (Craig and Craig, 2005), with the exception of T. taeniaeformis which had been recorded only in Canada (Mech, 1970). The finding of this latter wolf parasite in Serbia represents its first finding in the wolf host not only in Europe but in the entire Palearctic ecozone.

Overall, the prevalence of infection found in this study was much lower than that reported in recent papers. The taeniid species found in wolves in Serbia had lower prevalence in comparison to other European studies. In this study, the most prevalent helminth was $T$. hydatigena $(9.1 \%)$. This is one of the lowest prevalence 

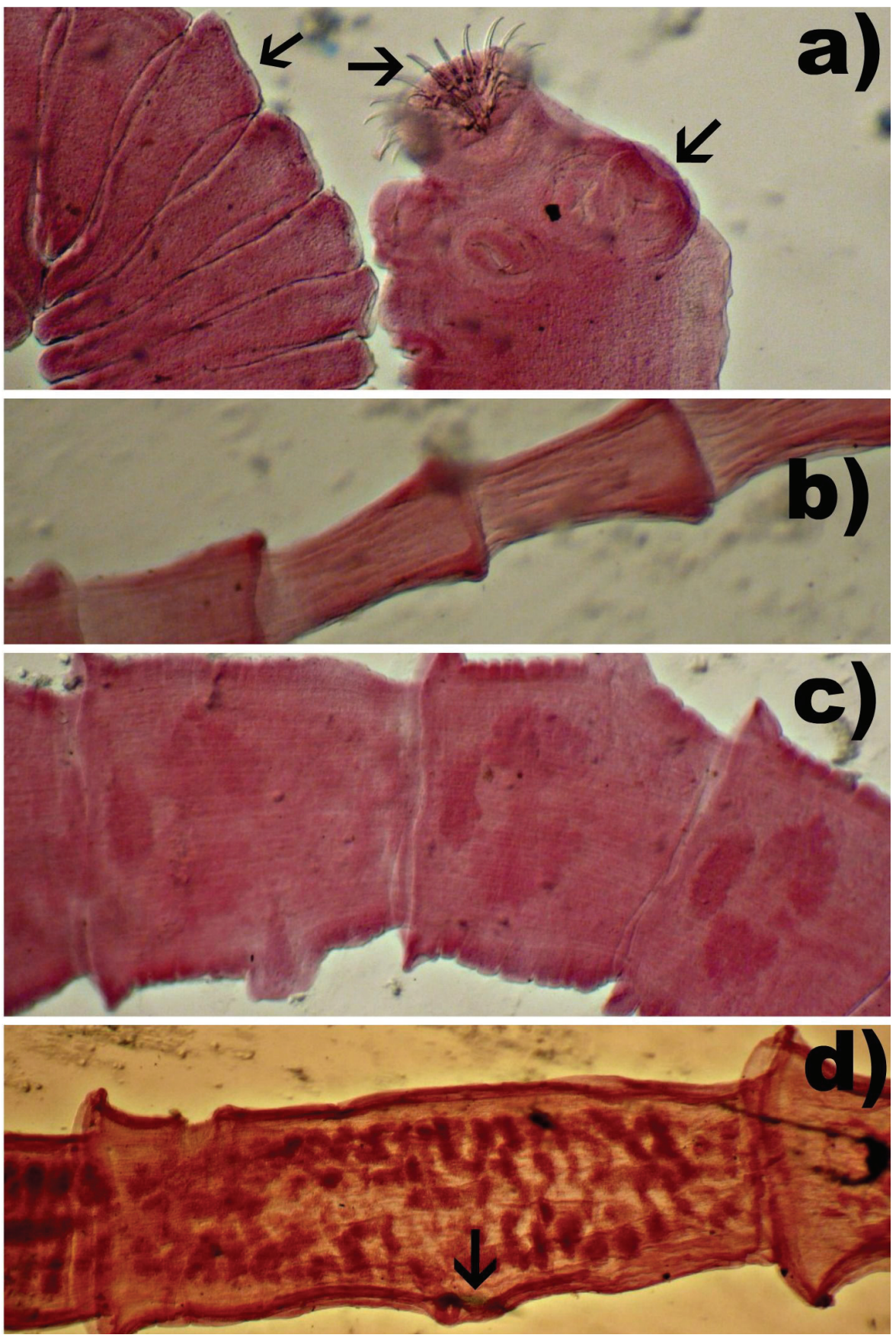

Fig. 2. First record of Taenia taeniaeformis in a wolf from the Palearctic ecozone.

Legend: a) scolex and strobila; arrows indicate immature proglottids, suckers and hooks; b) immature proglottids; c) mature proglottids; d) gravid proglottid; arrow indicates a genital pore 
values of this tapeworm recorded in European wolf populations and is most similar to the prevalence found in Estonia (12\%) and Portugal (11.8\%) (Moks et al., 2006; Guerra et al., 2013). Moreover, T. hydatigena was one of the two most prevalent gastrointestinal helminth species of wolves in all studies (Craig and Craig, 2005) with a prevalence in Europe up to 64\% as recorded in Spain (Segovia et al., 2003). In the only study published on helminths of the wolf in the Balkan region (Greece), T. hydatigena was not recorded (Papadopoulos et al., 1997).

Table 2

Prevalence of intestinal helminth infections in wolves (Canis lupus L.) according to years and seasons

\begin{tabular}{|c|c|c|c|c|c|c|c|c|c|c|}
\hline & \multicolumn{6}{|c|}{ Years } & \multicolumn{4}{|c|}{ Seasons } \\
\hline & 2009 & 2010 & 2011 & 2012 & 2013 & 2014 & Winter & Spring & Summer & Autumn \\
\hline Infected & 2 & 1 & 0 & 3 & 7 & 4 & 14 & 1 & 1 & 1 \\
\hline Non-infected & 11 & 21 & 12 & 26 & 12 & 3 & 65 & 13 & 1 & 6 \\
\hline Total & 13 & 22 & 12 & 29 & 19 & 7 & 79 & 14 & 2 & 7 \\
\hline Prevalence $(\%)$ & 15.4 & 4.5 & 0 & 10.3 & 36.8 & 57.1 & 17.7 & 7.1 & 50 & 14.3 \\
\hline
\end{tabular}

Taenia pisiformis and T. polyacantha were found to be less prevalent in this survey than in other studies from Europe: the prevalence of T. pisiformis was $2.9 \%$ in Portugal (Guerra et al., 2013), 4\% in Spain (Segovia et al., 2003), 7\% in Italy (Guberti et al., 1994) and 20.6\% in Latvia, while the prevalence of $T$. polyacantha was $11.8 \%$ in Latvia (Bagrade et al., 2009).

After T. hydatigena, T. multiceps has the second widest distribution among cestodes in Europe. This parasite has been found in Spain, Latvia and Estonia (Segovia et al., 2001; Segovia et al., 2003; Moks et al., 2006; Bagrade et al., 2009). The prevalence reported in these papers was much higher than that found in our study: it ranged between $27 \%$ in Estonia and $47.1 \%$ in Latvia.

To the best of our knowledge, $T$. serialis has not been found in central or northern Europe so far. This tapeworm in wolves has been described only in two studies from Spain with a prevalence of 4 and $4.3 \%$, respectively (Segovia et al., 2001; Segovia et al., 2003). Our finding represents the first reported occurrence of this cestode in a wolf host from a continental temperate climate zone of Europe. Only one trematode (A. alata) was found during this study. This trematode is one of the most common parasites of the wolf in Europe. According to the available literature, this digenean parasite has been found in almost every European country where wolves were examined for intestinal parasites (Spain, Latvia, Estonia and Poland) with the exception of Greece and Italy (Guberti et al., 1994; Papadopoulos et al., 1997; Segovia et al., 2001; Segovia et al., 2003; Moks et al., 2006; Popiołek et al., 2007; Bagrade et al., 2009). Moreover, in Northern Europe (Latvia and Estonia) A. alata was the intestinal parasite with the highest prevalence (85.3\%, Moks et al., 2006; 89\%, Bagrade et al., 2009), while in two sur- 
veys conducted in Southern Europe (Spain) its prevalence was low, 2 and 2.1\%, respectively (Segovia et al., 2001; Segovia et al., 2003), in conformity with the results obtained in this study.

Toxocara canis was the only nematode species found in wolves from Serbia. This nematode is the most common intestinal parasite, found in all studies carried out in Europe. Its prevalence values ranged from 4\% in Spain (Segovia et al., 2001) up to $16.6 \%$ in Greece (Papadopoulos et al., 1997). Compared to these results, the prevalence of T. canis in Serbia was the lowest (3.9\%) in Europe.

Following similar studies on other canid species, this survey was the first parasitological study conducted in Serbia on intestinal helminths of the wolf. All the helminth species identified in this study (Table 1) are known and common in other autochthonous canid species in Serbia. All nine species had previously been recorded in foxes (Pavlović and Kulišić, 2001; Pavlović et al., 2006; Pavlović et al., 2008). The same cestode species commonly occur (with a prevalence of 71.4\%) in golden jackals (Ćirović et al., 2015). The only two tapeworm species that are not found in golden jackals are T. polyacantha and T. taeniaeformis (Ćirović et al., 2015). Comparing the results obtained on the occurrence of intestinal helminths in stray dogs from the Belgrade area with the findings of this study, only four helminth species were common: A. alata, T. pisiformis, M. litteratus and T. canis (Kulišić et al., 1998). Red fox and stray dog populations had much higher prevalence values of intestinal parasites (Kulišić et al., 1998; Pavlović and Kulišić, 2001; Pavlović et al., 2006; Pavlović et al., 2008) than wolves, while golden jackals examined had similar, low prevalence (Ćirović et al., 2015). Only $T$. hydatigena was far more prevalent in wolves than in golden jackal and fox populations.

\section{Acknowledgements}

This study was supported by the Ministry of Education, Science and Technological Development of the Republic of Serbia (Contract TR 31009). The authors wish to express their gratitude to all collaborators in the field who helped in collecting the material for this study: Srđan Vučković, Gradimir Koturović, Nenad Mirković and Zoran Gubin.

\section{References}

Ansorge, H., Kluth, G. and Hahne, S. (2006): Feeding ecology of wolves Canis lupus returning to Germany. Acta Theriol. 51, 99-106.

Bagrade, G., Kirjušina, M., Vismanis, K. and Ozoliņš, J. (2009): Helminth parasites of the wolf Canis lupus from Latvia. J. Helminthol. 83, 63-68.

Boitani, L. (1992): Wolf research and conservation in Italy. Biol. Conserv. 60, 125-132.

Boitani, L. (2000): Action plan for the conservation of the wolves (Canis lupus) in Europe. Convention on the Conservation of European Wildlife and Natural Habitats (Bern Convention). Nature and Environment, No. 113, Council of Europe Publishing, Strasbourg, France. 76 pp. 
Bush, A. O., Lafferty, K. D., Lotz, J. M. and Shostak, A. W. (1997): Parasitology meets ecology on its own terms: Margolis et al. revisited. J. Parasitol. 83, 575-583.

Craig, H. L. and Craig, P. S. (2005): Helminth parasites of wolves (Canis lupus): a species list and an analysis of published prevalence studies in Nearctic and Palearctic populations. J. Helminthol. 79, 95-103.

Ćirović, D., Pavlović, I., Penezić, A., Kulišić, Z. and Selaković, S. (2015): Levels of infection of intestinal helminth species in the golden jackal (Canis aureus) from Serbia. J. Helminthol. 89, 28-33.

Delibes, M. (1990): Status and conservation needs of the wolf (Canis lupus) in the Council of Europe member states. Nature and Environment Series, Number 47. Council of Europe, Strasbourg, France.

Guberti, V., Stancampiano, L. and Francisci, F. (1994): Intestinal helminth parasite community in wolves (Canis lupus) in Italy. Parassitologia 35, 59-65.

Guerra, D., Armua-Fernandez, M. T., Silva, M., Bravo, I., Santos, N., Deplazes, P. and Carvalho, L. M. M. D. (2013): Taeniid species of the Iberian wolf (Canis lupus signatus) in Portugal with special focus on Echinococcus spp. Int. J. Parasitol.: Parasites Wildl. 2, 50-53.

Kozlov, D. P. (1977): Key to the Helminths of Carnivorous Mammals of the USSR. Moscow, Nauka.

Kulišić, Z., Pavlović, I., Milutinović, M. and Aleksić-Bakrac, N. (1998): Intestinal parasites of dogs and role of dogs in epidemiology of larva migrans in the Belgrade area. Helminthologia 35, 79-82.

Lucchini, V., Galov, A. and Randi, E. (2004): Evidence of genetic distinction and long-term population decline in wolves (Canis lupus) in the Italian Apennines. Mol. Ecol. 13, 523-536.

Mech, L. D. (1970): The Wolf. The Ecology and Behaviour of an Endangered Species. Natural History Press, New York.

Milenković, M. (1997): Taxonomic-biogeographic status and ecological/economical significance of the wolf (Canis lupus Linnaeus 1758) in Yugoslavia. PhD Thesis, University of Belgrade, Belgrade, Serbia.

Milenković, M., Paunović, M. and Ćirović, D. (2007): Action plan for wolf Canis lupus L., 1758 conservation in Serbia. Phase I - strategic plan. Institute for Biological Research 'Siniša Stanković', Belgrade.

Moks, E., Jõgisalu, I., Saarma, U., Talvik, H., Järvis, T. and Valdmann, H. (2006): Helminthologic survey of the wolf (Canis lupus) in Estonia, with an emphasis on Echinococcus granulosus. J. Wildlife Dis. 42, 359-365.

Papadopoulos, H., Himonas, C., Papazahariadou, M. and Antoniadou-Sotiriadou, K. (1997): Helminths of foxes and other wild carnivores from rural areas in Greece. J. Helminthol. 71, 227-232.

Pavlović, I. and Kulišić, Z. (2001): Trematodes in red foxes (Vulpes vulpes L.) caught in the area of Belgrade [in Serbian, with English abstract]. Veterinarski Glasnik 55, 35-40.

Pavlović, I., Kulišić, Z. and Stanojević, S. (2006): The nematodes of red foxes (Vulpes vulpes L.) hunted in Belgrade area. Lucrari Ştiințifice Medicina Veterinara 49, 396-399.

Pavlović, I., Tambur, Z., Doder, R., Kulišić, Z. and Jekić-Dimić, D. (2008): The cestodes of the red fox (Vulpes vulpes L.) caught in Serbia in the period 1994-2006. Veterinaria 57, 100-108.

Popiołek, M., Szczęsna, J., Nowak, S. and Mysłajek, R. W. (2007): Helminth infections in fecal samples of wolves Canis lupus L. from the western Beskidy Mountains in southern Poland. J. Helminthol. 81, 339-344.

Randi, E. (2011): Genetics and conservation of wolves Canis lupus in Europe. Mammal. Rev. 41, 99-111.

Randi, E., Lucchini, V., Christensen, M. F., Mucci, N., Funk, S. M., Dolf, G. and Loeschcke, V. (2000): Mitochondrial DNA variability in Italian and East European wolves: Detecting the consequences of small population size and hybridization. Conserv. Biol. 14, 464-473.

Rózsa, L., Reiczigel, J. and Majoros, G. (2000): Quantifying parasites in samples of hosts. J. Parasitol. 86, 228-232. 
Salvatori, V. and Linnell, J. (2005): Report on the conservation status and threats for wolf (Canis lupus) in Europe. Council of Europe T-PVS/Inf. 2005, 16.

Segovia, J. M., Guerrero, R., Torres, J. and Feliu, C. (2003): Ecological analyses of the intestinal helminth communities of the wolf, Canis lupus, in Spain. Folia Parasit. 50, 231-236.

Segovia, J. M., Torres, J., Miquel, L., Llaneza, L. and Feliu, C. (2001): Helminths in the wolf, Canis lupus, from north-western Spain. J. Helminthol. 75, 183-192.

Shimalov, V. V. and Shimalov, V. T. (2000): Helminth fauna of wolf (Canis lupus Linnaeus, 1758) in Belorussian Polesie. Parasitol. Res. 86, 163-164.

Sokal, R. R. and Rohlf, F. J. (1995): Biometry: The Principles and Practice of Statistics in Biological Research. Third edition. W. H. Freeman, New York. 887 pp.

Soulsby, E. J. L. (1982): Helminths, Arthropods and Protozoa of Domesticated Animals. Seventh edition. Lea \& Febiger, Philadelphia. 809 pp. 